\title{
A IMPORTÂNCIA DA VEDAÇÃO DO NEPOTISMO NA ADMINISTRAÇÃO PÚBLICA
}

\section{THE IMPORTANCE OF SEALING NEPOTISM IN PUBLIC ADMINISTRATION}

\author{
Kelson Djônata Ferraz Brito \\ Acadêmico do $10^{\circ}$ Período do Curso de Direito \\ Fundação Presidente Antônio Carlos de Teófilo Otoni - MG - Brasil \\ E-mail:
}

Thalles da Silva Contão

Professor Orientador. Professor do Curso de Direito da Universidade Presidente Antônio Carlos de Teófilo Otoni - MG - Brasil E:mail: thallesdasilvacontao@gmail.com

\section{Resumo}

O presente artigo tem como objetivo abordar a importância da proibição do nepotismo nas três esferas dos poderes, o Executivo, Legislativo e Judiciário no sistema brasileiro, bem como os graus de parentescos que podem ter a contratação ou nomeação nos cargos de primeiro escalão. O respectivo trabalho visa à abordagem de princípios dentro da administração pública, sendo eles, o Princípio da Impessoalidade, o Princípio da Moralidade e o Princípio da Eficiência. Este artigo visa a chegada do Nepotismo no Brasil com a promulgação da Constituição Federal de 1988, no qual a mesma traz os princípios mínimos norteadores da administração pública direta e indireta. Aborda-se aqui também a súmula vinculante do Supremo Tribunal Federal (STF) de número 13, bem como, o Decreto de número 7.203/2010 e a Lei 8.112/1990, dos servidores da União, em que traz em suas redações às vedações do Poder Judiciário, Poder Executivo e Poder Legislativo e as contratações de parentes dos agentes públicos. O artigo científico traz fatos históricos como a origem da palavra Nepotismo, bem como um personagem que foi um dos maiores praticantes do Nepotismo no Mundo e devido alguns casos de práticas de Nepotismo, os Países Democráticos perceberam a importância de se fazer proibição para que não prejudicasse o sistema administrativo, pois na atualidade é um ato imoral, impessoal e injusto.

Palavras-chaves: Nepotismo. Princípios. Súmula Vinculante $\mathrm{N}^{\circ} 13$.

\begin{abstract}
This article aims to address the importance of the prohibition of nepotism in the three spheres of power, the Executive, Legislative and Judiciary in the Brazilian system, as well as the degrees of kinship that may have the hiring or appointment in the first positions. The respective work aims to approach principles within the public administration, namely, the Principle of Impersonality, the Principle of Morality and the Principle of Efficiency. This article aims at the
\end{abstract}


arrival of Nepotism in Brazil with the promulgation of the Federal Constitution of 1988, in which it brings the minimum guiding principles of direct and indirect public administration. It also addresses here the binding summary of the Supreme Federal Court (STF) number 13, as well as Decree number 7.203 / 2010 and Law 8.112 / 1990, of the servers of the Union, in which it brings in its wording the prohibitions of the Judiciary Branch, Executive Branch and Legislative Branch and the hiring of relatives of public officials. The scientific article brings historical facts such as the origin of the word Nepotism, as well as a character who was one of the greatest practitioners of Nepotism in the World and due to some cases of Nepotism practices, the Democratic Countries realized the importance of making a ban so that it did not harm the administrative system, because today it is an immoral, impersonal and unjust act.

Keywords: Nepotism. Principles. Binding Summary No. 13.

\section{Introdução}

O nepotismo tem sua origem muito remota, que começou no Vaticano e depois se espalhou em uma escala global. Em Roma com o Papado e, no Brasil, com as então, Capitanias Hereditárias, até chegar aos dias atuais.

Com a chegada da Carta Magna de 1988, a prática de nomeações de parentes para administração pública passou ser proibido pela própria Administração, pois os princípios norteadores da Administração Pública, como tal os princípios da Impessoalidade, Moralidade e Eficiência, faz com que evitem a nomeação em cargos públicos e que sejam ocupados pelos parentes dos governantes.

Além dos princípios norteadores da administração pública, também há previsão no Estatuto dos Servidores Públicos da União, Lei 8.112/1990, que narra sua proibição ao manter sob seu comando a chefia imediata, em cargo ou função de confiança, cônjuge, companheiro ou parente até o segundo grau civil.

Na esfera do Poder Executivo a vedação da prática do Nepotismo se encontra no Decreto n 7.203/2010. Segundo Fernanda Marinela, 2013:

Esses diplomas proíbem a presença de cônjuge, companheiro, ou até parente na linha reta, colateral ou por afinidade, até o terceiro grau, inclusive dos respectivos membros ou juízes vinculados ao tribunal, assim como de qualquer servidor ocupante de cargo de direção ou assessoramento, para exercer cargo em comissão ou função de confiança, para as contratações temporárias e para as contratações diretas com dispensa ou exigibilidade de licitação em que o parentesco exista entre os sócios, gerentes ou diretores da pessoa jurídica. (MARINELA, 2013, p. 65). 
Para a doutrinadora, Fernanda Marinela diz que os princípios mínimos da Constituição Federal de 1988 trazem na sua redação os diplomas de proibição ou vedação à prática do Nepotismo para cônjuge, companheiro, ou parente na linha reta, colateral ou por afinidade, até o terceiro grau; sobretudo, a proibição para os familiares dos juízes que possuem vínculos ao tribunal, fazendo desta maneira a tentativa de evitar o Nepotismo aos seus respectivos órgãos para os cargos de direção, assessoramento, cargo em comissão ou função de confiança para seus parentes em até o terceiro grau

O Decreto de $\mathrm{n}^{\circ} 7.203 / 2010$, no qual a ilustre doutrinadora discorre, deixa claro que a vedação a prática do Nepotismo deve ser sempre observado os diplomas, isto é, os princípios da carta magna de 1988, destarte, para todos os setores dos Três Poderes da União, sendo eles, Legislativo, Executivo e Judiciário, para que possam sempre andar em conformidade com os princípios norteadores de uma boa administração pública, fazendo assim, a vedação do Nepotismo para seus órgãos e familiares dos Agentes Políticos.

\section{Origem da palavra Nepotismo}

A etimologia da palavra Nepotismo vem do Latim “nepos”, que significa sobrinho, neto ou descendente. Começou esta prática no Vaticano com os Papas que nomeavam os seus parentes para cargos de Cardeais da Igreja Católica Apostólica Romana, então depois começou a espalhar pelo mundo em uma escala global.

Originalmente a palavra aplicava-se com exclusividade no âmbito das relações do Papa com seus parentes em particularidade com o Cardeal-sobrinho, mas nos dias atuais é utilizado como sinônimo de concessão de privilégios ou cargos para parentes nos cargos públicos.

Um dos maiores nepotistas no mundo foi Napoleão Bonaparte, que em 1809, três de seus irmãos eram reis de países que Napoleão Bonaparte conquistou com seu poderoso exército.

Já no Brasil, no período da Monarquia ficou conhecida esta prática como pistolão, pois foi muito empregada para referenciar um parente ou conhecido que obteve vantagem ou ganhos advindos do nepotismo ou favoritismo.

\section{Constituição Federal de 1988}

A Constituição Federal da República de 1988, em seu artigo 37, "Caput” e inciso II, traz em sua redação o que se pode chamar de "pedra angular" da principiologia que rege a Administração Pública.

O artigo supracitado possui em seu texto, in verbis: 
Art. 37. A administração pública direta e indireta de qualquer dos poderes da União, dos Estados, do Distrito Federal e dos Municípios obedecerá aos princípios de legalidade, impessoalidade, moralidade, publicidade e eficiência e, também ao seguinte:

$\mathrm{I}-(\ldots)$

II - A investidura em cargo ou emprego público depende de aprovação prévia em concurso público de provas ou de provas e títulos, de acordo com a natureza e a complexidade do cargo ou emprego, na forma prevista em lei, ressalvada as nomeações para cargo em comissão declarado em lei de livre nomeação e exoneração; (BRASIL, 1988).

O texto em epígrafe diz que a administração pública deve total e absoluta obediência aos chamados princípios constitucionais mínimos, que diante das doutrinas neoconstitucionalistas, possuem força normativa da norma direta.

\section{Princípio da Impessoalidade}

O princípio da impessoalidade sobrepõe que a atuação do agente público deve basearse na ausência de subjetividade, ficando o mesmo impedido de consolidar quaisquer inclinações e interesses pessoais, próprios ou de terceiros. A impessoalidade tem como objetivo a igualdade de tratamento que a Administração deve aplicar aos administrados que se encontrem em idêntica situação jurídica, representando, nesse aspecto, uma parcela do princípio da isonomia.

Para o doutrinador Celso Antônio Bandeira Mello, o princípio da impessoalidade traduz a ideia de que a Administração tem de tratar a todos os administradores sem discriminações, benéficas ou detrimentosas. Nem favoritismo, nem perseguições são toleráveis. Simpatias ou animosidades pessoais, políticas ou ideológicas não podem interferir na atuação administrativa. E ainda completa: o princípio em causa não é senão o próprio princípio da igualdade ou isonomia. (MELLO, 2010, p. 114)

O referido princípio também pode ser analisado sob dois aspectos diferentes: primeiro, quanto ao dever de atendimento ao interesse público, tendo o administrador a obrigação de agir de forma impessoal, abstrata, genérica, protegendo sempre a coletividade; segundo, que a atividade administrativa exercida por um agente público, faça com que seja imputada ao órgão ou entidade e não ao próprio agente.

\section{Princípio da Moralidade}

O princípio da moralidade faz exigências que a Administração e seus agentes atuem em conformidade com princípios éticos aceitáveis socialmente. Este princípio se relaciona com a 
ideia de honestidade, exigindo a estrita observância de padrões éticos, de boa-fé, de lealdade, de regras que assegurem uma boa administração, bem como a disciplina interna na Administração Pública.

O princípio da moralidade administrativa não se confunde com a moralidade comum, pois a moral comum é subjetiva, seu íntimo, o que é moral para um não é para o outro, já a moralidade administrativa visa regras de boa administração, pela ideia de função administrativa, interesse do povo, de bem comum. Moralidade administrativa está ligada ao conceito de bom administrador.

A Constituição Federal, ao recepcionar o princípio da moralidade, determinou a necessidade de sua proteção e a responsabilização do administrador público amoral ou imoral. Para tanto, encontram-se no ordenamento jurídico muitos mecanismos para repelir ou impedir atos de imoralidade como, por exemplo, regras sobre improbidade administrativa, no artigo 37 , parágrafo $4^{\circ}$, da CF/88 e na Lei ${ }^{\circ}$ 8.429/1992; os crimes de responsabilidade do Presidente da República e de mais outros agentes políticos, artigo 85, inciso $\mathrm{V}$, da $\mathrm{CF} / 88$; os também chamados remédios constitucionais tem a principal a então nomeada ação popular que está prevista no artigo $5^{\circ}$, inciso LXXIII, que quiçá da $\mathrm{CF} / 88$, e várias outras leis que fazem jus ao princípio outrora mencionado.

Enfim, infringi-lo implicará violação ao próprio Direito, às regras constitucionais, sobretudo, configurando um ato ilícito sujeita à invalidação ou anulação.

\section{Princípio da Eficiência}

Este princípio, que ganhou notoriedade de princípio constitucional expresso por intermédio da Emenda Constitucional n 19/1998, muito embora já existisse implicitamente na Lei Maior, o mesmo princípio traz condições que são imprescindíveis para a efetiva proteção do interesse público.

A eficiência coloca exigência que a atividade administrativa seja exercida com presteza, perfeição e rendimento funcional. Consiste na busca inacabável de resultados práticos de produtividade, de economia, com a consequente redução de desperdícios do dinheiro público e rendimentos típicos da iniciativa privada, sendo que, nessa situação, o lucro é dos usuários; quem ganha é o bem comum. 
O controle ao Nepotismo contribui com a eficiência da Administração Pública, pois oportuniza bons servidores à máquina administrativa.

\title{
7 Artigo 103-A da Constituição Federal de 1988
}

Nos dizeres do artigo 103-A, in verbis:

\begin{abstract}
Art. 103-A. O supremo Tribunal Federal poderá, de oficio ou por provocação, mediante decisão de dois terços dos seus membros, após reiteradas decisões sobre matéria constitucional, aprovar súmula que, a partir de sua publicação na imprensa oficial, terá efeito vinculante em relação aos demais órgãos do Poder Judiciário e à administração pública direta e indireta, nas esferas federal, estadual e municipal, bem como proceder à sua revisão ou cancelamento, na forma estabelecida em lei. (BRASIL, 1988).
\end{abstract}

A súmula tem por objetivo a validade, a interpretação e a eficácia de normas determinadas pelos seus membros do Supremo Tribunal Federal como se pode observar pelo seu texto do artigo 103-A extraído da Carta Maior de 1988.

No que diz respeito a súmula em matéria do direito administrativo, pode-se extrair do artigo outrora mencionado que logo que a maioria dos membros do STF tiver uma decisão sobre determinado assunto, a mesma terá efeito imediato além de se tornar vinculante para outros órgãos do Poder Judiciário, logo à administração pública direta e indireta, tanto na órbita Federal, Estadual e Municipal terão também que observar àquela súmula vinculante.

\section{Conceito de Súmula}

No Direito brasileiro, a chamada súmula é um apontamento ou registro que tem a interpretação pacífica ou majoritária adotada por um Tribunal a respeito de um tema específico, a partir de um julgamento de diversos casos análogos, com a dupla finalidade de tornar pública a jurisprudência para a sociedade bem como de promover a uniformidade entre as decisões.

A súmula constitui um conjunto de, no mínimo três acórdãos do mesmo Tribunal que adotam o mesmo entendimento ou interpretação de preceito jurídico em tese, fazendo desta maneira que surja a chamada súmula que serve como um direcionamento, uma dica de como àquele órgão superior entende àquela matéria que outrora se tornou súmula que antes era decisões reiteradas. 
Com a finalidade de resguardar os princípios administrativos e de tornar o mais claro possível o conteúdo constitucional, eis então que surge a súmula vinculante $\mathrm{n}^{\circ} 13$, expedida pelo Supremo Tribunal Federal (STF), que declara a ofensividade na Carta Magna, a prática do nepotismo.

Nos dizeres da Súmula Vinculante $n^{\circ} 13$ :

A nomeação de cônjuge, companheiro ou parente em linha reta, colateral ou por afinidade, até o terceiro grau, inclusive, da autoridade nomeante ou de servidor da mesma pessoa jurídica investido em cargo de direção, chefia ou assessoramento, para o exercício de cargo de comissão ou de confiança ou, ainda, de função gratificada da administração pública direta e indireta em qualquer dos poderes da União, dos Estados, do Distrito Federal e dos Municípios, compreendido o ajuste mediante designações recíprocas, viola a Constituição Federal (BRASIL, 2008).

Percebe-se que a referida súmula, estabelece no poder judiciário, a proibição às práticas do nepotismo aos seus respectivos órgãos; isto para fazer cumprir o princípio da impessoalidade e que a máquina pública tenha celeridade em suas obrigações. Contudo, esta súmula pecou em não fazer menção aos cargos políticos, sendo que para cargos de natureza política, isto é, cargos de confiança ou comissionados de primeiro escalão pode se praticar o "nepotismo", pois os cargos denominados Agentes Políticos estão longe da súmula vinculante do STF, deixando assim uma pequena fenda para a prática de contratações de familiares na seara política, pois para os cargos de primeiro escalão, cargos de confiança ou chefia pode haver nomeações, como por exemplo, Secretários Municipais, Estaduais e Ministros de Estado, pois os mesmos são cargos de confiança do poder Executivo.

Como já mencionado anteriormente, a Constituição Federal de 1988 é um conjunto de normas que tem por finalidade a suprema harmonia entre si. Se existe uma previsão legal de uma norma que autorize a nomeação livre para cargos em comissão e há consolidação de tais princípios, mesmo que sejam implícitas, as regras devem ser conciliadas em prol da coletividade, que é o bem maior que a Suprema Carta visa proteger.

Tendo como visão a moralização do funcionalismo público, o Estatuto dos Servidores da União (Lei 8.112/1990), em seu artigo 117, inciso VIII, manter sob sua chefia imediata, em cargo ou função de confiança, cônjuge, companheira, ou parente até segundo grau civil.

Destarte, a regra acima transcrita, não há uma norma regulamentando a questão em todos os níveis da Federação, haja vista, que não impede a contratação de parentes. Ainda, sobre a esfera Federal, a regra é nitidamente ultrajada por meio de contratação de parentes de graus 
superiores aos que a norma faz proibição e aos que tem afinidade dos agentes políticos, até mesmo de "parentes trocados", isto é, um agente político nomeia parente de outro agente político e vice-versa, denominados casos de Nepotismo Cruzado.

Nos dizeres de Telmo da Silva Vasconcelos ${ }^{1}$ :

O controle do excesso e dos abusos no provimento dos cargos em comissão são competência constitucional posta aos mecanismos de controle, notadamente o Ministério Público e os Tribunais de Contas. Bastaria que tais entes fiscalizassem e exigissem o exato cumprimento das determinações constitucionais, ou seja, que o provimento dos cargos em comissão viesse a ocorrer somente para atividades de direção, chefia ou assessoramento, condicionado, evidentemente, o provimento, à comprovação da capacidade técnica do indicado. Para os casos em que há legislação específica a situação fica mais fácil de ser controlada, bastando à exigência do cumprimento da lei.

O texto em epígrafe que o autor nos traz, diz que, bastaria para cada ente da Federação a simples e eficaz fiscalização dos Agentes Públicos em cargos de comissão para atividades de direção, chefia e assessoramento o cumprimento da lei e as observações dos princípios constitucionais para se ter uma boa administração para com seus usuários.

Pode-se observar, portanto, que o administrador deve pautar-se, acima de tudo, pelos conceitos morais em que o ordenamento jurídico dita como regra, buscando assim, sempre a finalidade da lei, sem perseguir seus anseios pessoais ou favoritismos familiares; caso não faça esta observância, sucumbirá em um outro ato, que é a improbidade administrativa que atenta contra a administração pública e os princípios da Constituição Federal de 1988. Também é válido destacar sobre o Princípio da Supremacia do Interesse Público sobre o Privado, portanto o Agente político deve sempre primar por aquilo que a lei e as regras constitucionais impõem para os seus servidores.

Em análise a violação do Princípio da Moralidade como já fora mencionado anteriormente, é válido salientar que o nepotismo pode ser enquadrado como então citado improbidade administrativa, por ultrajar o artigo 11 da lei n ${ }^{\circ}$ 8.429/1992, vide: "Constitui ato de improbidade administrativa que atenta contra os princípios da administração pública qualquer ação ou omissão que viole os deveres de honestidade, imparcialidade, legalidade e lealdade às instituições (BRASIL, 1992)."

\footnotetext{
${ }^{1}$ https://www.direitonet.com.br/artigos/exibir/6548/Nepotismo
} 
A improbidade administrativa caracteriza por ato ilegal praticado no âmbito da Administração Pública, quando um agente público age de forma desleal e desonesta no cumprimento das funções públicas.

A corrupção é um exemplo clássico de improbidade administrativa, pois o agente público usa de má-fé e desonestidade com o escopo de atingir um beneficio próprio ou de terceiro, além de ultrajar diretamente a Constituição Federal de 1988. Entretanto, não é considerado crime, conforme a lei 8.429/1992 define, mas é considerado conduta de natureza cível. Deste modo o agente público que comete improbidade administrativa não pode responder por um crime.

\section{Nepotismo no Ordenamento Jurídico Brasileiro}

As práticas do nepotismo são incompatíveis com o atual ordenamento jurídico brasileiro, especialmente após a atual Constituição Federal de 1988, que promove claramente princípios como a impessoalidade, a moralidade administrativa e a eficiência que estão em um patamar de grande importância no exercício da atividade administrativa.

$\mathrm{O}$ artigo 37, inciso II da $\mathrm{CF} / 88$ prevê de forma clara a exigência da realização de concurso público para assim ter uma tentativa de afastar as facilidades adquiridas em razão de parentesco, permitindo que qualquer um que preencha de forma satisfatória todas as condições mínimas exigidas na Carta Magna de 1988 possa participar sem que haja favoritismo ou interesses de terceiros.

O nepotismo ocorre quando um agente público usa de sua posição de poder para nomear, contratar ou favorecer um ou mais parentes.

A vedação ao nepotismo não exige edição de lei formal, pois a proibição é extraída diretamente dos princípios constitucionais que norteiam a atuação administrativa. Não é preciso ter uma lei especifica falando sobre o nepotismo pelo fato de que o nepotismo é algo impessoal, ele fere o princípio da impessoalidade, ele é ato imoral porque fere o princípio da moralidade e também ineficiente porque o agente público estará contratando um terceiro interessado não porque ele é bom no que faz, mas sim porque ele é parente de algum agente político importante. Por ferir estes três princípios o nepotismo já é vedado diretamente pela Constituição da República Federativa do Brasil de 1988, não precisando de uma lei específica que o proíba. 
Os cargos de confiança e comissão estão previstos no artigo 37, inciso V da Carta Máxima de 1988, para tanto os mesmos dispositivos há uma diferença entre eles.

Nos dizeres da Constituição Federal, artigo 37, inciso V, in verbis:

Art. $37(\ldots)$

$\mathrm{V}$ - as funções de confiança, exercidas exclusivamente por servidores ocupantes de cargo efetivo, e os cargos em comissão, a serem preenchidos por servidores de carreira nos casos, condições e percentuais mínimos previstos em lei, destinam-se apenas às atribuições de direção, chefia e assessoramento; (BRASIL, 1988).

Como supracitado o inciso da Constituição Federal, as funções de confiança são àqueles servidores ocupantes de cargo efetivo, isto é, que já atuam junto a Administração Pública. Já os cargos de comissão podem ser preenchidos de servidores de carreira, ou seja, alguém que já atua junto a Administração Pública, alguém que já ocupa cargo efetivo, mas também se pode observar que o ocupante de cargo em comissão pode ser uma pessoa que não tem vinculo anterior com o poder público. Ocorre que, a Constituição Federal de 1988 determina é que no caso de cargo em comissão, futuramente uma lei deverá estabelecer um percentual mínimo de cargos em comissão preenchidos por servidores de carreira.

Entretanto, há um ponto em comum entre estes dispositivos, pois os cargos de função de confiança e cargos em comissão servem apenas para atividades diferenciadas, isto é, para cargos de Direção, Chefia e Assessoramento.

Em análise a este parágrafo uma lei não poderá e nem pode criar função de confiança ou cargos em comissão para atividades meramente administrativas e se porventura acontecer a criação da lei, então haverá uma inconstitucionalidade por ultrajar a Constituição da República, pois estará violando diretamente o artigo 37 , inciso $\mathrm{V}$ da $\mathrm{CF} / 88$.

\subsection{Nepotismo-Cruzado}

Pode-se considerar Nepotismo-Cruzado a nomeação por parte dos membros do Judiciário, Executivo e Legislativo da União, Estados, Distrito Federal e Municípios, de parentes uns dos outros.

O nepotismo-cruzado é caracterizado por troca de favores "entre os poderes"; é a contratação de indivíduos de um Poder para outro, por exemplo: O prefeito do município "X" 
contrata para atuar no município, em cargo comissionado, o filho do vereador "Y" que em seguida contrata para o seu gabinete o cunhado do prefeito.

Esta prática é tão imoral tanto quanto o nepotismo puramente dito, pois se trata de Chefe do Poder Executivo com o Poder Legislativo agindo de má-fé para com a sociedade local porque se trata de contratação de parentes de um Prefeito para Câmara dos Vereadores e parente de um dos vereadores contratado pelo Prefeito, fazendo assim surgir o que a Doutrina e Jurisprudência chamam de Nepotismo-Cruzado.

Tal prática é vedada pelo Ordenamento Jurídico brasileiro, contudo, em Comarcas menores esta "troca de favores" entres os Poderes são notórios, pois não há tanta fiscalização bem como os cidadãos de certos Municípios desconhecem o que é Nepotismo-Cruzado, que é um ato ilegal e imoral que por muito das vezes passa despercebido aos nossos olhos.

Pode se observar tal prática pelas ementas julgadas em órgãos superiores que ainda nos dias de hoje é muito comum a tentativa de ultrajar a vedação do nepotismo e nepotismocruzado, vide:

\section{EMENTA}

RECURSO EM MANDADO DE SEGURANÇA. NEPOTISMO. PRÁTICA OFENSIVA AOS PRINCÍPIOS CONSTITUCIONAIS. VIOLAÇÃO DE DIREITO LÍQUIDO E CERTO. INOCORRÊNCIA. SÚMULA VINCULANTE No 13/STF. APLICABILIDADE.

(STJ - RMS: 31947 GO 2010/0068775-4, Relator: Ministro HAMILTON CARVALHIDO, Data de Julgamento: 16/12/010, T1 - PRIMEIRA TURMA, Data de Publicação: DJe 02/02/2011). ${ }^{2}$

\section{EMENTA}

PROCESSUAL CIVIL. AGRAVO INTERNO NO AGRAVO EM RECURSO ESPECIAL. ENUNCIADO ADMINISTRATIVO $\mathrm{N}^{\circ}$ 3/STJ. IMPROBIDADE ADMINISTRATIVA. NEPOTISMO CRUZADO. CONFIGURAÇÃO DO ATO DE IMPROBIDADE ADMINISTRATIVA AFIRMADA PELO TRIBUNAL A QUO COM BASE NO CONJUNTO FÁTICO E PROBATÓRIO CONSTANTE DOS AUTOS. SÚMULA 7/STJ. AGRAVO INTERNO NÃO PROVIDO.

(STJ - AgInt no AREsp: 1019652 RS 2016/0305535-2, Relator: Ministro MAURO COMPBELL MARQUES, Data de Julgamento: 04/05/2017, T2 - SEGUNDA TURMA, Data de Publicação: DJe 10/05/2017). ${ }^{3}$

\footnotetext{
${ }^{2}$ https://stj.jusbrasil.com.br/jurisprudencia

${ }^{3}$ https://stj.jusbrasil.com.br/jurisprudencia
} 
Estas ementas traz uma ideia de como até hoje os Agentes Políticos tentam ultrajar, burlar ou ultrapassar as várias proibições sobre o Nepotismo. Não é incomum vê a tentativa de se praticar o Nepotismo, principalmente na seara política.

A tentativa de se praticar o Nepotismo é comum mesmo sendo um tema já endurecido pela própria Constituição Federal de 1988, porém não é respeitado por alguns Agentes Políticos, pois os mesmos acham que pode se praticar o Nepotismo desrespeitando sua vedação; já outros Agentes Políticos desconhecem sua vedação, concorrendo assim para a prática do Nepotismo e até mesmo para o Nepotismo-Cruzado.

\subsection{Decreto 7.203/2010}

Este decreto traz consigo uma "barreira”, uma vedação à prática do nepotismo no âmbito federal dos órgãos e entidades da administração pública direta e indireta, visando a máxima proteção principalmente contra as nomeações de familiares de Ministros do Poder Executivo Federal, como dispõe o artigo $3^{\circ}$ "Caput" do respectivo Decreto.

Art. $3^{\circ}$, Decreto $7.203 / 2010$, in verbis:

Art. $3^{\circ}$. No âmbito de cada órgão e de cada entidade, são vedadas as nomeações, contratações ou designações de familiar de Ministro de Estado, familiar da máxima autoridade administrativa correspondente ou, ainda, familiar de ocupante de cargo em comissão ou função de confiança de direção, chefia ou assessoramento(...) (BRASIL, 2010).

O artigo do Decreto já mencionado faz a vedação de parentes de Cargos de primeiro escalão que são de Ministros de Estado, fazendo a proibição de Cônjuge, companheiro ou parente em linha reta ou colateral por consanguinidade ou afinidade até o terceiro grau, isto é, uma tentativa de proibir ou coibir tal prática ilegal e imoral.

O Decreto supracitado traz em sua redação a vedação do nepotismo para que a administração pública possa ter impessoalidade, pois os cargos em comissão ou função de confiança devem agir para seus usuários de serviços sem subjetividade em relação aos terceiros, também a administração pública deve ter moralidade, isto é, que os agentes possam atuar de forma ética em relação aos princípios da administração pública, sobretudo deve ter a administração pública à chamada eficiência, pois tem que ser célere e agir com perfeição para com a administração pública.

Haja vista, que o Decreto 7.203/2010, trouxe em seu texto os chamados princípios mínimos da administração pública para que os chefes dos três Poderes possam de antemão, analisar quando for realizar nomeações aos seus Secretários e Ministros para assim evitar que cometam a prática do nepotismo na administração pública. 


\section{CONSIDERAÇÕES FINAIS}

Conclui-se, que ainda nos dias de hoje com tantas leis, proibições, súmulas, decretos e várias outras proibições pode-se vê que temos algumas tentativas das práticas do Nepotismo e do Nepotismo-Cruzado, pois os chefes dos poderes sejam eles, Legislativo, Executivo ou Judiciário, "venda os olhos" quanto à prática do nepotismo, fazendo desta maneira a inobservância da proibição por questões políticas e até mesmo por anseios de poder.

Haja vista, que o Ordenamento Jurídico Brasileiro ao longo do período vem melhorando de forma efetiva para acabar de vez com esta prática ilegal, imoral e injusta, por meio de severas leis que trouxeram em seus textos a vedação por ser considerado o nepotismo um ato atentatório ao Estado-Democrático de Direito em todo o mundo.

A legislação sobre a vedação ao nepotismo no Brasil vem melhorando cada vez mais, sobretudo, as doutrinas do Direito Administrativo, que vêm sendo discutido muito sobre o tema e a forma de combate a essa prática no Ordenamento Jurídico Brasileiro, que em sua maioria ainda ocorre principalmente no Poder Legislativo e Executivo, isto é, no campo da política brasileira, que infelizmente por mais proibições que se faça, ainda temos casos no Poder Judiciário julgando as tentativas de burlar a vedação ao nepotismo na seara política para favorecer terceiros que não fazem jus a essa nomeação ou contratação.

Ainda sobre esta reflexão, desde 1988 com a promulgação da Constituição da República Federativa do Brasil até 2019, houve um avanço significativo quanto à prática do nepotismo, pois, por mais que ainda exista alguns casos de nepotismo no Brasil em todo campo da União, considera-se uma diminuição significativa desta prática imoral e também punições para quem pratica o nepotismo, seja ele Nepotismo-Cruzado ou Nepotismo direto.

É sabido que o nepotismo por mais que seja muito discutido ainda é um tema que carece de melhorias para que haja a efetiva concretização da proibição.

A importância da vedação ao nepotismo na administração pública é imprescindível para que um Estado-Democrático de Direito possa funcionar em acordo com os princípios da administração para que assim tenhamos uma Ordem Pública séria e efetiva para com seus usuários e sem fazer favoritismos ou benesses para parentes ou parentes afins. 
Desta maneira, as proibições precisam ser feitas para cargos de primeiro escalão que são de Ministros de Estado, pois esta brecha deixa uma incógnita sobre se é legal ou ilegal, entretanto, em análise sobre essa temática, deixa claro que os cargos de primeiro escalão é um meio "legal" para praticar o nepotismo, mas que infelizmente não se caracteriza por não ter proibição a respeito.

\title{
THE IMPORTANCE OF THE SEALING OF NEOTISM IN PUBLIC ADMINISTRATION
}

\begin{abstract}
This article aims to address the importance of the prohibition of nepotism in the three spheres of power, the Executive, Legislative and Judiciary in the Brazilian system, as well as the degrees of kinship that can be hired or appointed in senior positions. Their work aims at addressing principles within public administration, namely the Principle of Impersonality, the Principle of Morality and the Principle of Efficiency. This article aims at the arrival of Nepotism in Brazil with the promulgation of the Federal Constitution of 1988, where it brings the minimum guiding principles of direct and indirect public administration. This article also deals with the binding ruling of the Supreme Court (STF) number 13, as well as Decree number 7.203 / 2010 and Law 8,112 / 1990, of the Union's servants, in which they write in their wording the Judiciary, Executive and Legislative Power and the hiring of relatives of public agents. The scientific article brings historical facts such as the origin of the word Nepotism, as well as a character who was one of the greatest practitioners of Nepotism in the world and due to some cases of Nepotism practices the Democratic Countries realized the importance of making a prohibition so as not to harm the administrative system, because at present it is an immoral, impersonal and unfair act.
\end{abstract}

Keywords: Nepotism. Principles. Binding Precedent $N^{\circ} 13$.

\section{REFERÊNCIAS}

BRASIL. Constituição da República Federativa do Brasil de 1988. Disponível em: http://www.senado.leg.br/atividade/const/con1988 12.07.2016/art. 37 .asp. Acesso em: 12 Nov. 2018

BRASIL. Decreto $n^{\circ} 7.203$ do ano de 2010; Brasília, 4 de junho de 2010. Disponível em: http://www.planalto.gov.br/ccivil 03/ Ato2007-2010/2010/Decreto/D7203.htm. Acesso em: 15 Nov. 2018

BRASIL. Lei nº 8.112 do ano de 1990, Estatuto dos Servidores da União; Senado Federal, 18 de abril de 1991. Disponível em: http://www.planalto.gov.br/ccivil 03/LEIS/L8112cons.htm. Acesso em: 13 Nov.2018 
BRASIL. Lei $\mathrm{n}^{\circ} 8.429$ do ano de 1992, Improbidade Administrativa; Rio de Janeiro, 2 de junho de 1992. Disponível em: http://www.planalto.gov.br/ccivil 03/LEIS/L8429.htm. Acesso em: 15 Nov. 2018

BRASIL. Súmula Vinculante do STF n 13. Disponível em:

http://www.stf.jus.br/portal/jurisprudencia/menusumario.asp?sumula=1227. Acesso em: 13 Nov.2018

JUSBRASIL. Jurisprudência. Disponível em: https://stj.jusbrasil.com.br/jurisprudencia. Acesso em: 12 Jul 2019

MAIA. Luciana Andrade. Nepotismo. Direito Net, 2006. Disponível em: https://www.direitonet.com.br/artigos/exibir/6548/Nepotismo. Acesso em: 14 Nov. 2018 MARINELA. Fernanda. Direito Administrativo. 2013 - $7^{\circ}$ Ed - Niteri: Impetus. Pág. 692 MELLO. Celso Antônio Bandeira. Curso de Direito Administrativo. 2010 - $27^{\circ}$ Ed. rev. e atual. até a E.C 64 - São Paulo. Malheiros Editores. Pág. 114

PILON. Marcelo. Nepotismo, Nepotismo-Cruzado e Transnepotismo. Voto Consciente Jundiaí, 2013. Disponível em: https://votoconscientejundiai.com.br/nepotismo-nepotismocruzado-e-transnepotismo-2/. Acesso em: 8 Jul. 2019.

WIKIPÉDIA. Nepotismo; Disponível em: https://pt.wikipedia.org/wiki/Nepotismo. Acesso em 12 Nov. 2018

WIKIPÉDIA. Súmula. Disponível em: https://pt.wikipedia.org/wiki/Súmula. Acesso em: 8 Jul. 2019 